\title{
Early initiations of first antenatal care visit and associated factor among mothers who gave birth in the last six months preceding birth in Bahir Dar Zuria Woreda North West Ethiopia
}

Yibeltal Alemu* and Amanu Aragaw

\begin{abstract}
Background: Timing of Antenatal care booking is one of the basic components of antenatal care services; that helps to early detection, managing, and prevention of problems during the pregnancy and helps the mother to receive full packages of antenatal care services. However, in the world including Ethiopia, significant numbers of pregnant mothers were not booking the follow up on the recommended time. The main aim of this study was to assess the prevalence and factors that associated with the early timing of antenatal care visit in Bahir Dar Zuria District, North West Ethiopia.

Methods: A community-based cross-sectional study was conducted. A total of 410 mothers have participated. Data were collected through the interview from March 1 to 30/2018 using a structured and pre-tested questionnaire. Data were clear, code, and enter into Epi-info version 7.1 and export to SPSS for farther analysis. Both bivariate and multivariate analyses were used. On bivariate analysis $p$-value, less than 0.2 were used to select the candidate variable for multivariate analysis. $P$-value and confidence interval were used to measure the level of significance on multivariate analysis and those variables whose $P$-value $<0.05$ were considered as statically significant.

Results: The prevalence of early timing of ANC in the study area was 46.8\%; with [95\% Cl 40.5, 51.8]. Distances [AOR 2. $47,95 \% \mathrm{Cl} ; 1.4,4.2]$, Knowledge on the timing of ANC [AOR 2.1; 95\% Cl; 1.2, 3.7], No under-five children [AOR 2.7; 95\% $\mathrm{Cl} ; 1.3,5.8]$, having one under-five children [AOR 2.2; 95\% Cl; 1.1, 4.5], and wanted pregnancy [AOR 2.4, 95\% Cl, 1.3, 4.7] were affects the early timing of ANC.

Conclusions: The prevalence of early timing of ANC was high when compared to the national figure and the Sub-Saharan country. Accessibility of health services, knowledge on the timing of ANC, under-five children, and desire for pregnancy were factors that affect the early timing of ANC.
\end{abstract}

Keywords: ANC, Maternal health, Pregnancy, Utilization, Ethiopia

* Correspondence: yibeltalalemu6@gmail.com

Department of Reproductive Health, College of Medicine and Health Science,

Bahir Dar University, P.O.Box 79, Bahir Dar, Ethiopia

(c) The Author(s). 2018 Open Access This article is distributed under the terms of the Creative Commons Attribution 4.0 International License (http://creativecommons.org/licenses/by/4.0/), which permits unrestricted use, distribution, and reproduction in any medium, provided you give appropriate credit to the original author(s) and the source, provide a link to the Creative Commons license, and indicate if changes were made. The Creative Commons Public Domain Dedication waiver (http://creativecommons.org/publicdomain/zero/1.0/) applies to the data made available in this article, unless otherwise stated. 


\section{Plain English summary}

Antenatal care is the care which provided for the mother during pregnancy to improve the health of the mother and unborn baby. World health organization is recommended for booking the services before the first trimester or 12 weeks of gestation. However, according to our country Ethiopia ministry health, it's acceptable until 16 weeks of gestation. This study was trying to answer the level and associated factors through structured interview questionnaires.

The participants were asked their socio-demographic characteristics, reproductive characteristics, about antenatal care service utilization, and the challenges they face during antenatal care service utilization.

Of 400 participants 187 of the participants were initiated the follow-up before 16 weeks of gestation. This study reveals that the average month mothers were starting antenatal care visit at 16 weeks and 5 days. Short distances from the facilities, knowledge on the timing of ANC, not having under-five children, having one under-five child, and wanted or planned pregnancy was the main factor that affects the early timing of antenatal care visit.

In conclusion, the prevalence of early timing of ANC visit in the study area was high in comparison to the national figure. Factors that responsible for early initiation of ANC services were the accessibility of the services, knowledge about the timing of ANC, a desire of pregnancy, and under-five children. Policy action will be required to farther improve the timely booking of ANC.

\section{Background}

Pregnancy is one of the most important periods in the life of a woman, a family, and a society [1]. While, because of these physiological changes that occur during pregnancy, mother and her baby were facing life treating problems. To avert the problem, there are different maternal health care services were provided for minimizing the problem. One of the services is Antenatal care (ANC) [2]. The aim of ANC service is to prevent health problems that affect both the fetus and mother and to ensure that each newborn child has a good start [3].

Nevertheless, true progress has been made globally in terms of increasing access and use, there are high numbers of maternal deaths and stillbirths were occurred [4]. Globally around 2.6 million stillbirths annually and 830 maternal deaths every day occur due to the pregnancyrelated cause. Among all deaths, $99 \%$ occurred in the developing countries as compared as $1 \%$ in developed countries [5]. Many maternal and prenatal deaths occur in women who have not received timely, inadequate and no utilization of ANC [6]. Early antenatal care attendance during the first three months of gestation plays a major role in detecting and treating complications that occur during pregnancy [2].

The timing of Antenatal care booking is one of the basic components of ANC services. It helps to early detection, managing, and prevent problems that occur during the pregnancy time. According to WHO Focus antenatal care model recommendation, all pregnant mothers are better to start ANC booking within the first trimester of pregnancy (within 12 weeks) [3]. In addition, now a time World Health Organization adopt a new ANC model that recommend to increase the numbers of contact from four visits to eight contacts for the aim of reducing prenatal mortality and to improve women experiences of care $[3,7]$. Actually, this new Antenatal care model still is not practicable in Ethiopia. However, according to the Federal Democratic Republic of Ethiopia Ministry of Health recommendation, the timing of ANC booking is acceptable until 16 weeks of gestation [8].

Existing evidence in the global shows that the prevalence of early timing of antenatal care visits were around $43 \%$. According to the report, there is a high discrepancy between developed and developing regions [9]. The report showed that $85 \%$ of mothers in the developed region start their ANC follow up earlier but it was below $45 \%$ and less than $25 \%$ in the developing countries and sub-Sahara region respectively [10]. According to different demographic health survey report in sub-Sahara countries shows that the prevalence of early timing of ANC visit ranges from 17.6 to $20 \%[8,11,12]$.

According to Ethiopian demographic health survey, 2016 report indicates that 20\% of pregnant mothers started their Antenatal care visit at the first trimester of pregnancy from that $44 \%$ of the mothers live in the urban, start ANC visit at the first trimester of pregnancy compared to $17 \%$ in the rural community [8]. Different literature conducted in Ethiopia also shows that the prevalence of early timing of ANC visit ranges from 17 to $41 \%$ [13-15].

Studies conducted in developing countries showed that residence, educational status of the mother, husband occupation, parity and planned or wanted pregnancy was factors for late ANC booking [16, 17]. Studies conducted in the urban Ethiopia shows that age of the mother, educational status of the mother, previous history of ANC, perceive adequacy of ANC, low monthly income, receiving advice on when to start ANC visits, household food insecurity, parity, urine test as a means of pregnancy recognition, and unplanned pregnancy was a determinant of the early timing of ANC visits [13, 14, 18-22].

Studies conducted in rural Ethiopia showed that age of the mother, parity, planned pregnancy, media access, knowledge about the time of ANC booking, and advised to book within 12 weeks was affected the timing of antenatal care 
visit $[23,24]$. There are limited finding on the prevalence and factors associated with the early timing of ANC booking in the study area as well as in the country. For this situation, a cross-sectional study is important to address the gap. Therefore assessing the prevalence and factors that associated with early timings of antenatal care visit are important for setting intervention that helps to improve the utilization of ANC services.

\section{Methods and materials Study area}

The study was conducted at Bahir Dar Zuria District; it is founded around Bahir Dar city administration $564 \mathrm{~km}$ far from the capital Addis. The District consists of 9 rural clusters. The total population of the District was estimated 220,410 from those, around $48.6 \%$ were female. Two thousand five hundred ninety-nine mothers in the district gave birth from August first to January last 2018; of that $86.4 \%$, mothers have a history of ANC. In the District, there are 9 health centers, and 224 health professionals and 32 health extension workers were enrolled [25].

\section{Study design and period}

A Community-based cross-sectional study was conducted from March 1 to 30, 2018.

\section{Source populations}

All mothers who have a history of ANC and gave birth in the last six months in Bahir Dar Zuria district.

\section{Study population}

Those selected mothers who have a history of ANC and gave birth in the study in the last six months during data collection period in Bahir Dar Zuria district.

\section{Inclusion criteria}

All mothers who have a history of ANC and gave live birth.

\section{Exclusion criteria}

Women excluded from the study were those who are not hearing and seriously ill during the data collection period.

\section{Sample size determination}

The sample size for the study was calculated using a single population proportion formula with the following assumptions. Based on findings from a previous study conducted in the central zone of Tigray (Ethiopia) [26]. The proportion of women who start ANC before the fourth month was found to be $41 \%$ By assuming a margin of error of $5 \%, Z_{\alpha / 2}=$ value for $95 \%$ CI (1.96), proportion $=41 \%$, and the non-response rate of $10 \%$, a sample size of 410 women obtained.

\section{Sampling procedures and technique}

All 9 clusters in the study area were included. The health extension workers immunization registration book was used to easily identify mothers who gave birth for the last six months in the District and whether they have a history of ANC from August 1 to January 30, 2018, G.C. Subsequently, the lists of the entire mother who have history ANC were found from the health extension worker registration books. Then the simple random sampling technique was used to select the study participants from those who have a history of ANC.

\section{Data collection tools and procedures}

Data were collected using a structured questionnaire which adopted and modified from Ethiopian DHS and other previous studies. The questionnaire was prepared in English and it translated into Amharic then translated back to English to check for consistency.

Data were collected via interview. Seven diploma holder nurses were recruited for data collection, 3 supervisor degree holder nurses were assigned for supervisory activities along with the principal investigator.

\section{Data quality controls}

The prepare questionnaire and tools were translated into Amharic and then translated back to English for consistency. The Amharic version of the questionnaire was pre-test among $41(10 \%)$ of the sample population in the Cluster not include in the study. Training was provided for the data collectors and supervisors on the objectives, relevance of the study, how to keep the confidentiality of the information and techniques of interviews for two consecutive days. The supervisors have supervised the data collection process every day and the principal investigator also cheeks the collected questionnaire for completeness every other day.

\section{Data processing and analysis}

Data were cleaned, code and entered into Epi-info version 7.1 then exported to SPSS version 23 for analysis. Descriptive analysis was carried out to see the distribution of independent variables. Binary logistic regression was used to examine associations between the dependent variable and each independent variable. Based on the bivariate analysis those factors whose crude associations to the timing of antenatal care booking at $p<$ 0.2 was entered into the multivariate analysis to get adjusted odds ratio.

The strength of association was determined by using a crude odds ratio in the bivariate analysis and adjusted odds ratio in multivariate analysis. $P$-values 
and $95 \%$ confidence interval was used to determine the level of significance of the association. $P<0.05$ considered as statistically significant. Hosmer and Lemeshow Test were used for checking the model fitness of logistic regressions.

\section{Results}

Out of 410 mothers who have a history of Antenatal care follow up in Bahir Dar Zuria District, 400 complete the interview administer questionnaires. Therefore the data analysis was made based on 400 respondents that have been completed the interview. The response rate was $97.56 \%$.

\section{Socio-cultural characteristics}

Among the total participants, one hundred twenty-eight (32\%) of the respondents were in the age group of 25-29 years. The mean ages of the respondents were 28.47 ( $\mathrm{SD} \pm 5.47)$. Three hundred ninety-four $(98.5 \%)$ of the respondents were followers of Orthodox religion the rest were Muslim. Three hundred ninety-eight (99.5\%) of the respondents were Amhara ethnicity. Three hundredninety $(97.6 \%)$ of the respondents were married. Fifty $(12.5 \%)$ of the respondents were attended formal education.

Eighty-four (21\%) and $85(21.5 \%)$ of the household were rich and richest wealth index respectively. Two hundred sixty-two $(65.5 \%)$ of the respondents were poor household decision making power. One hundred fourteen $(28.5 \%)$ of the respondent traveling more than one hour to reach the ANC services. The median time travel to reach the ANC services was $60 \mathrm{~min}$. Three hundred sixty-seven $(91.8 \%)$ of the respondents were traveling on foot. (Table 1).

\section{Reproductive history}

Three hundred twenty-two (80.2\%) of the respondent were knowledgeable about the timing of antenatal care. Two hundred-thirteen (53.3\%) of the respondents were multi-gravid. Two hundred twenty-five $(56.3 \%)$ of the respondents were multi-Para. Fifty-six (14\%) of the participants has had an unwanted pregnancy. (Table 2.

\section{Prevalence of early timing of antenatal care booking}

Among the participants one hundred eight-seven (46.7\%) with $95 \%$ CI $[40.5,51.8]$ of the respondents, were booking there first ANC visit before four months of pregnancy. The average months of starting the follow up were 16 weeks and 5 days. One hundred fifty-seven (39.3\%) of the respondents were started the follow up at four to five months. (Fig. 1).
Table 1 The socio- cultural characteristics of the mother in Bahir Dar Zuria district North West Ethiopia 2018 $(n=400)$

\begin{tabular}{|c|c|c|}
\hline Variables & Frequency & Percent (\%) \\
\hline \multicolumn{3}{|l|}{ Age } \\
\hline$<20$ years & 9 & 2.3 \\
\hline 20-24 years & 89 & 22.2 \\
\hline $25-29$ years & 128 & 32 \\
\hline 30-34 years & 113 & 28.3 \\
\hline$\geq 35$ years & 61 & 15.2 \\
\hline \multicolumn{3}{|l|}{ Educational status of the mother } \\
\hline Not attained formal education & 350 & 87.5 \\
\hline Primary level (Grade 1to 8) & 41 & 10.3 \\
\hline Secondary (Grade 9 to 12) & 9 & 2.2 \\
\hline \multicolumn{3}{|l|}{ Marital status } \\
\hline Single & 6 & 1.5 \\
\hline Married & 390 & 97.6 \\
\hline Divorced & 3 & 0.8 \\
\hline Widowed & 1 & 0.3 \\
\hline \multicolumn{3}{|l|}{ Occupation of the mother } \\
\hline Farmer & 384 & 96 \\
\hline Trader & 12 & 3 \\
\hline Student & 3 & 0.75 \\
\hline Governmental employer & 1 & 0.25 \\
\hline \multicolumn{3}{|l|}{ Wealth index } \\
\hline Poorest & 67 & 16.75 \\
\hline Poor & 74 & 18.5 \\
\hline Middle & 90 & 22.5 \\
\hline Rich & 84 & 21 \\
\hline Richest & 85 & 21.25 \\
\hline \multicolumn{3}{|l|}{ Accompanion during ANC visit } \\
\hline Yes & 267 & 66.8 \\
\hline No & 133 & 33.3 \\
\hline \multicolumn{3}{|l|}{ Family size } \\
\hline $1-3$ & 89 & 22.2 \\
\hline $4-5$ & 142 & 35.5 \\
\hline Above 5 & 169 & 42.3 \\
\hline \multicolumn{3}{|l|}{ Numbers of under five children } \\
\hline No under five & 108 & 27 \\
\hline One under five & 234 & 58.5 \\
\hline Two under five & 58 & 14.5 \\
\hline \multicolumn{3}{|l|}{ Distance } \\
\hline Less than $30 \mathrm{~min}$ & 146 & 36.5 \\
\hline 30 min to one hour & 140 & 35 \\
\hline More than one hour & 114 & 28.5 \\
\hline
\end{tabular}


Table 2 reproductive characteristics of the mother in Bahir Dar Zuria district North West Ethiopia 2018( $n=400)$

\begin{tabular}{lll}
\hline Variable & Frequency & Percent \\
\hline Numbers of pregnancy & 80 & 20 \\
One & 213 & 53.2 \\
2 to 5 & 107 & 26.8 \\
$\geq 5$ & & \\
Parity & 91 & 22.7 \\
Primipara & 225 & 56.3 \\
Multi-para & 84 & 21 \\
Grand multi-para & \\
Knowledge of the mother on the timing of ANC & \\
Knowledgeable & 322 & 80.5 \\
Not knowledgeable & 88 & 19.5 \\
\hline
\end{tabular}

\section{Factors that associated with early initiations first} antenatal care visit

In the bivariate analysis, family size, decision-making power, distance, wealth index, knowledge, under five, age, accompanying person, urine test, a desire of pregnancy were candidate variable for multivariate analysis. And on multivariate analysis, distances, knowledge, under-five children, and desire for pregnancy were true determinants of early time antenatal care visit at the $p$-value less than 0.05 .

The factors that directly affect the early timings of Antenatal care visit were short distances from the facility, knowledge on the timing of ANC, not having under-five children, having one under-five child, and wanted or planned pregnancy were factors that affect the early timing of antenatal care visit.

The odds of early timing of ANC visit among mothers who travel less than 30 min to reach ANC services were 2.47 times higher than those who travel more than one hour [AOR 2.47, 95\% CI; 1.4,4.2]. The odds of early timing of antenatal care visit among mothers who were knowledgeable on the timing of ANC visit were 2.1 times higher than the counterparts [AOR 2.1; 95\% CI; 1.2, 3.7]. The odds of early timing of ANC visit among mothers who have no under five children 2.7 and one under five children 2.2 times higher than those who had two under-five children [AOR 2.7; 95\% CI; 1.3,5.8], [AOR 2.2; 95\% CI; 1.1,4.5] respectively. In addition to this, the odds of early timing of ANC visit among mothers with wanted pregnancy were 2.4 times higher than the counterparts [AOR 2.4, 95\% CI, 1.3, 4.7]. (Table 3).

\section{Discussion}

The prevalence of early timing of ANC visits was $46.8 \%$. The factors that directly affect the early timing of ANC visits were distances, knowledge of the mother on the timing of ANC, numbers of under-five children, and desire of pregnancy.

This finding shows that the prevalence of early first time antenatal care visits was 46.8 with $95 \%$ CI [40.5, 51.8] which is in line with the prior study conduct in Gonder Ethiopia 47.4\% [18], and central Tigray Ethiopia $41 \%$ [14]. However the finding of this study was lower than study conduct in Addis Ababa Ethiopia 58\% [27], and Nepal 70\% [17]. The difference might be due to the study area in Addis Ababa there are accessible and available services and more aware of the existing services than the study area.

The finding of this study was higher than study conduct in Gedeo Zone Ethiopia 35.4\% [20], Ethiopian DHS $20 \%$ [ 8 ], and in the Global estimate 24\% [10]. This inconsistency could be attributed to the scope of the study, the fact that EDHS covered more remote. It is also significant to note down the time gap between the EDHS and this study.

This study also shows that mothers who live within short distances from the health facility were more likely early initiate ANC visit than those who travel more than one hour. This finding was in line with the finding of previous study conduct in Cameron [28]. This might be due to women live

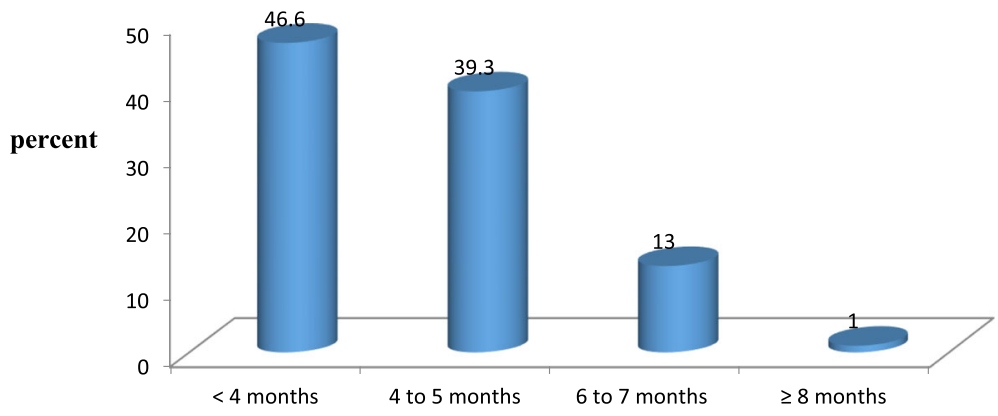

Fig. 1 Timing of first ANC booking among ANC utilized mothers in Bahir Dar Zuria District North West Ethiopia 2018. The figure showed that among all participants, $46.7 \%$ of the respondents, were booking there first ANC visit before four months of pregnancy and $39.3 \%$ of the respondents were started the follow up at four to five months. In addition, 13 and $1 \%$ of the respondents were booking there first ANC at six to seven; and eight and after months respectively 
Table 3 Bivariate and multivariable association of factors, with the timing of ANC initiation in Bahir Dar Zuria District, North West Ethiopia 2018. $(n=400)$

\begin{tabular}{|c|c|c|c|c|c|}
\hline \multirow[t]{2}{*}{ Variable } & \multicolumn{2}{|c|}{ Early ANC initiation } & \multirow{2}{*}{$\begin{array}{l}\text { COR }(95 \% \\
\text { Cl) }\end{array}$} & \multirow{2}{*}{$\begin{array}{l}\text { AOR }(95 \% \\
\mathrm{Cl})\end{array}$} & \multirow{2}{*}{$\begin{array}{l}p- \\
\text { value }\end{array}$} \\
\hline & Yes & No & & & \\
\hline \multicolumn{6}{|l|}{ Distance } \\
\hline Less than $30 \mathrm{~min}$ & 70 & 44 & $3(1.9,5.3)$ & $2.47(1.4,4.2)^{*}$ & 0.002 \\
\hline $30 \mathrm{~min}$ to $1 \mathrm{~h}$ & 70 & 76 & $1.8(1,2.9)$ & $1.6(0.98,2.6)$ & 0.71 \\
\hline More than $1 \mathrm{~h}$ & 47 & 93 & 1 & 1 & \\
\hline \multicolumn{6}{|l|}{ Accompanying person } \\
\hline Yes & 135 & 132 & $1.59(1,2.4)$ & $1.3(0.86,2.2)$ & \\
\hline No & 52 & 81 & 1 & 1 & \\
\hline \multicolumn{6}{|l|}{ Family size } \\
\hline$<5$ & 92 & 71 & $1.94(1.3,2.9)$ & $1.4(0.62,2.1)$ & \\
\hline$\geq 5$ & 95 & 142 & 1 & 1 & \\
\hline \multicolumn{6}{|l|}{ Knowledge on ANC } \\
\hline Knowledgeable & 165 & 157 & $2.67(1.5,4.5)$ & $2.1(1.2,3.7)^{*}$ & 0.016 \\
\hline Not knowledgeable & 22 & 56 & 1 & 1 & \\
\hline \multicolumn{6}{|c|}{ Numbers of under five children } \\
\hline No under five & 58 & 50 & $4(1.9,8.3)$ & $2.7(1.3,5 \cdot 8)^{*}$ & 0.014 \\
\hline One under five & 116 & 118 & $3.4(1.6,6.6)$ & $2.2(1.1,4.5)^{*}$ & 0.030 \\
\hline Two under five & 13 & 45 & 1 & 1 & \\
\hline \multicolumn{6}{|l|}{ Age of the mother } \\
\hline$\leq 24$ years & 58 & 40 & $2.39(1.2,4.6)$ & $1.7(0.85,3.5$ & \\
\hline 25 to 34 & 106 & 135 & $1.29(0.7,2.3)$ & $1.2(0.66,2.25)$ & \\
\hline$\geq 35$ & 23 & 38 & 1 & 1 & \\
\hline \multicolumn{6}{|c|}{ Wanted or planned pregnancy } \\
\hline Yes & 173 & 171 & $3(1.6,5.7)$ & $2.4(1.3,4.7)^{*}$ & 0.008 \\
\hline No & 14 & 42 & 1 & 1 & \\
\hline
\end{tabular}

in a developing country spent more times for activities like drawing water, household chores, rearing children and for agricultural activities rather than their health. As a result, they didn't think to attain the health facility for receiving ANC services because they have no time to go there. In addition to this, it may impose them for extra costs for transportation as well as loss from agricultural production.

This study also explains that mothers who have had knowledgeable on the timing of ANC were more likely to early initiate the ANC services than those not knowledgeable. This finding was consistent in meta-analysis study conduct in Ethiopia [29], and Southern Ethiopia [30, 31] this might be due to knowledge is important to realize the existing services and the timing of initiating ANC visits. In addition to this, high illiteracy level in the community may cause poor knowledge in the community.

Mothers who want her pregnancy were more likely to start the follow up early than the counterpart. This finding was in line with previous study conduct in Debre Markos
Ethiopia [32], Sothern Ethiopia [33], Ethiopia [29], Tigray Ethiopia [34], South Africa [35], and Nepal [17]. This might be due to when the mother prefers the pregnancy she is eager to keep the health of the baby. Due to that, they are excited to attain the follow up earlier.

In addition in this study the odds of early initiations of ANC visit among women who have no under-five children 2.7 and one under-five children 2.2 times higher than those who had two under-five children [AOR 2.7; 95\% CI; 1.3,5.8], [AOR 2.2; 95\% CI; 1.1,4.5] respectively. There are limited finding with regard to the relation between timing of initiation and numbers of under-five children in the previous study but in this study numbers of under-five children was one of the determinant factors for the timing of initiation of ANC. This might be due to women may responsible for caring for their baby.

\section{Conclusion}

The prevalence of early initiation of ANC in the study area was high in comparison to the national prevalence 
of the country. The factor that responsible for early initiation of ANC services were distance, knowledge on the timing of ANC, a desire of pregnancy, and less and family size.

\section{Recommendation}

For federal and regional health bureau to increase the awareness of timings of antenatal care utilization and increase access and availability of family planning method for preventing unintended pregnancy.

\section{Limitation}

The finding of this study was not triangulated on qualitative finding.

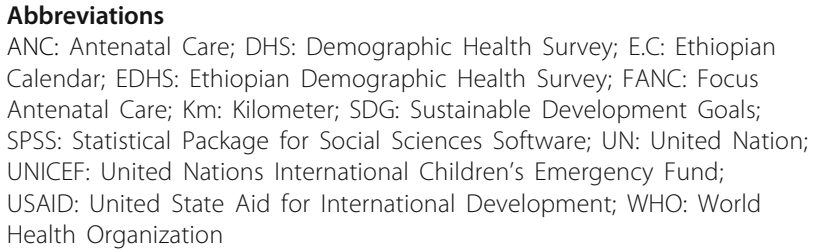

Abbreviations

ANC: Antenatal Care; DHS: Demographic Health Survey; E.C: Ethiopian Calendar; EDHS: Ethiopian Demographic Health Survey; FANC: Focus Antenatal Care; Km: Kilometer; SDG: Sustainable Development Goals; SPSS: Statistical Package for Social Sciences Software; UN: United Nation; UNICEF: United Nations International Children's Emergency Fund; USAID: United State Aid for International Development; WHO: World Health Organization

\section{Acknowledgements}

First of all, I would like to thank Bahir Dar University College of Medicine and Health Sciences, School of Public Health.

I would like to also thank the Bahir Dar Zuria District health office staff, health professional they work in the health centers and health extension workers in the Cluster for their invaluable support through the whole process.

Finally, I am also grateful to the supervisors and data collectors who have committed themselves throughout the study period and to all participants who were a volunteer to participate in the study.

\section{Funding}

Bahir Dar University has funded this research

\section{Availability of data and materials}

The original data from the survey is available from action for the early timing of antenatal care visit in an excel spreadsheet.

\section{Authors' contributions}

Y.A. performs the development of manuscript, develop the survey questioners, supervised the data collection and analysis of the data. A.A. supports the methodology of the study. All authors read and approved the final manuscript.

\section{Ethics approval and consent to participate}

The ethical clearance was received from Bahir Dar University College of Medicine and Health Science ethical and clearance review committee with the ethical protocol number of 014/18-01. The permission letter was received from Amhara regional state health bureau, West Gojjam Health office, and Bahir Dar Zuria District health office.

Informed verbal consent was taken in every questionnaire for every mother and based on her agreement the data collections took place. Information was provided for all participants about the objective, the purpose or the contents of the study as well as their rights to refusal and discontinuation of the study and reassuring the confidentiality how to handle and use the data.

\section{Consent for publication}

Written consent for publication was received from the participant with regard to all the detail that explain the participants.

\section{Competing interests}

The authors declare that they have no competing interests.

\section{Publisher's Note}

Springer Nature remains neutral with regard to jurisdictional claims in published maps and institutional affiliations.

Received: 12 October 2018 Accepted: 23 November 2018

Published online: 12 December 2018

\section{References}

1. World Health Organization (WHO), Pregnancy 2018.

2. Abou-Zahr CL, Wardlaw TM. Antenatal care in developing countries: promises, achievements, and missed opportunities: an analysis of trends, levels, and differentials, 1990-2001. In: World Health Organization; 2003.

3. World Health Organization (WHO). Antenatal care randemization trial. Geneva; 2002

4. World Health Organization (WHO). Provision of effective antenatal care: integrated management of pregnancy and childbirth (IMPAC). Geneva: Standards for maternal and neonatal care (1.6), Department of making pregnancy safer; 2006.

5. World Health Organization (WHO). In: M.a.R. Health, editor. Maternal Mortality, global health observation data; 2016.

6. Oyerinde K. Can antenatal care result in significant maternal mortality reduction in developing countries. J Community Med Health Educ. 2013;3(2):2-3.

7. World Health Organization (WHO), New ANC recommendation for positive pregnancy experience 2016.

8. Ethiopian Central Statistics Agency (ECSA), Ethiopian demographic health survey (EDHS). 2016.

9. World Health Organization (WHO). In: S.a.r. health, editor. More women worldwide receive early antenatal care, but great inequalities remain; 2018 .

10. Moller A-B, et al. Early antenatal care visit: a systematic analysis of regional and global levels and trends of coverage from 1990 to 2013. Lancet Glob Health. 2017;5(10):e977-83

11. Kenya National Bureau of Statistics, Kenyan Demographic, And health survey 2014

12. The National Population Commission Federal Republic of Nigeria, Nigeria demographic and health survey 2013. 2014

13. Gebremeskel F, Dibaba Y, Admassu B. Timing of first antenatal care attendance and associated factors among pregnant women in Arba Minch town and Arba Minch district, Gamo Gofa zone, South Ethiopia. J Environ Public Health. 2015;2015.

14. Gebreamlak $G$, et al. Timing of first focused antenatal care booking and associated factors among pregnant mothers who attend antenatal care in central zone, Tigray, Ethiopia. BMC research notes. 2017;10(1):608.

15. Sanni $Y$, et al. Timing and adequate attendance of antenatal care visits among women in Ethiopia. PLoS One. 2017;12(9):e0184934.

16. Thin A, et al. Late initiation of antenatal care and its determinants: hospital-based cross-sectional study. International Journal Of Community Medicine And Public Health. 2017:3(4):900-5.

17. Paudel YR, Jha T, Mehata S. Timing of first antenatal care (ANC) and inequalities in early initiation of ANC in Nepal. Front Public Health. 2017:5:242.

18. Belayneh T, Adefris M, Andargie G. Previous early antenatal service utilization improves timely booking: a cross-sectional study at the University of Gondar Hospital, north West Ethiopia. J Pregnancy. 2014;2014.

19. Gebrekidan K, Worku A. Factors associated with late ANC initiation among pregnant women in select public health centers of Addis Ababa, Ethiopia: unmatched case-control study design. Pragmatic and observational research. 2017:8:223

20. Abuka T, Alemu A, Birhanu B. Assessment of timing of first antenatal care booking and associated factors among pregnant women who attend antenatal Care at Health Facilities in Dilla town, Gedeo zone, southern nations, nationalities and peoples region, Ethiopia, 2014. J Preg Child Health. 2016:3(258):2

21. Kondale $\mathrm{M}$, et al. Timing of first antenatal care visit and associated factors among pregnant women attending antenatal clinics in Halaba Kulito governmental health institutions, 2015. J Women's Health Care. 2016:5(308): 2167-0420.1000308.

22. Zegeye AM, Bitew BD, Koye DN. Prevalence and determinants of early antenatal care visit among pregnant women attending antenatal care in Debre Berhan Health Institutions, Central Ethiopia. Afr J Reprod Health. 2013;17(4). 
23. Getasew, M., K. Teketo, and A. Mekonnen, Antenatal care service utilization and its associated factors among mothers who gave live birth in the past one year in Womberma Woreda, north West Ethiopia. Epidemiology: Open Access, 2015. 5(Special Issue 2).

24. Geta MB, Yallew WW. Early initiation of antenatal care and factors associated with early antenatal care initiation at health facilities in southern Ethiopia. Advances in Public Health. 2017;2017.

25. Bahir Dar Zuria district, Quarterly and Yearly report 2017.

26. Gidey G, et al. Timing of first focused antenatal care booking and associated factors among pregnant mothers who attend antenatal care in central zone, Tigray, Ethiopia. BMC research notes. 2017;10(1):608.

27. Gulema $H$, Berhane $Y$. Timing of first antenatal care visit and its associated factors among pregnant women attending public health facilities in Addis Ababa, Ethiopia. Ethiopian journal of health sciences. 2017;27(2):139-46.

28. Tolefac PN, et al. Why do pregnant women present late for their first antenatal care consultation in Cameroon? Maternal health, neonatology and perinatology. 2017;3(1):29.

29. Tesfaye $\mathrm{G}$, et al. Delayed initiation of antenatal care and associated factors in Ethiopia: a systematic review and meta-analysis. Reprod Health. 2017; 14(1):150.

30. Dembelu M, et al. Assessment of timely initiation of first ANC visit and associated factors among pregnant mothers in Wolayita Soddo public health facilities. Soddo Town: Wollayita Zone, SNNPR, Ethiopia; 2016.

31. Geta MB, Yallew WW. Early Initiation of Antenatal Care and Factors Associated with Early Antenatal Care Initiation at Health Facilities in Southern Ethiopia. Advances in Public Health. 2017;2017(Article ID: 1624245:6.

32. Ewunetie $A A$, et al. DELAY on first antenatal care visit and its associated factors among pregnant women in public health facilities of Debre Markos town, north West Ethiopia. BMC Pregnancy and Childbirth. 2018;18:173.

33. Gebremeskel F, Dibaba Y, Admassu B. Timing of First Antenatal Care Attendance and Associated Factors among Pregnant Women in Arba Minch Town and Arba Minch District, Gamo Gofa Zone, South Ethiopia. J Environ Public Health. 2015;2015(ID 971506):7.

34. Lerebo W, Kidanu A, Tsadik M. Magnitude and Associated Factors of Late Booking for Antenatal Care in Public Health Centers of Adigrat Town, Tigray, Ethiopia. Clinics Mother Child Health. 2015;12:171. https://doi.org/10.4172/ 2090-7214.1000171.

35. Ebonwu J, et al. Determinants of late antenatal care presentation in rural and peri-urban communities in South Africa: a cross-sectional study. PLoS One. 2018;13(3):e0191903.

Ready to submit your research? Choose BMC and benefit from:

- fast, convenient online submission

- thorough peer review by experienced researchers in your field

- rapid publication on acceptance

- support for research data, including large and complex data types

- gold Open Access which fosters wider collaboration and increased citations

- maximum visibility for your research: over $100 \mathrm{M}$ website views per year

At $\mathrm{BMC}$, research is always in progress.

Learn more biomedcentral.com/submissions 